\title{
Risk Assessment and Prioritization of ERP Implementation Based on BSC
}

\author{
Somaieh Alavi ${ }^{1^{*}}$, Shohreh Peivandzani ${ }^{2}$, Seyedmehdi Mirmohammadsadeghi ${ }^{1}$ \\ ${ }^{1}$ Department of Industrial Engineering, Faculty of Engineering, Shahid Ashrafi Esfahani University, Isfahan, Iran \\ ${ }^{2}$ Research Scholar, Iran Zamin Bank, Isfahan, Iran
}

Received 28 December 2020; Revised 21 February 2021; Accepted 27 February 2021; Published 01 March 2021

\begin{abstract}
Successful implementation of an Enterprise Resource Planning (ERP) system has many benefits for organizations, while its failure can have irreparable damage. Identifying the critical success and failure factors in implementing these systems seems essential. Therefore, evaluating the risk of implementing the organization's resource planning before starting the project is necessary. Failure Modes and Effects Analysis (FMEA) should be assessed and analyzed. Then, for each risk, risk management strategies are mentioned and prioritized using the TOPSIS method. After categorizing the organization's risks in four dimensions of stakeholders, growth and learning, process, and finance and ranking them based on FMEA, it was determined that the stakeholder dimension is in the first place, which shows the effectiveness of this dimension in advancing ERP implementation. The second place is given to growth and learning, which can be concluded to what extent education and knowledge management can reveal their effects on the project. The third and fourth ranks are the dimensions of process and finance, respectively, which, although the concern of most organizations to implement ERP is the financial dimension, is in the last rank of the category.
\end{abstract}

Keywords: Enterprise Resource Planning (ERP); Risk; Balanced Scorecard (BSC); Failure Modes and Effects Analysis (FMEA).

\section{Introduction}

The role of information technology in the business activities of companies is expanding rapidly. As the complexity of products, services and customer expectations increases, compelling market pressures drive companies to use advanced software to maintain their performance $[1,2]$. For organizations to be successful, managers need to have an integrated system of information. Enterprise Resource Planning (ERP) consists of software packages integrating various functions and simplifying the flow of information. It is equipped with standard methods and the latest information technology tools for effective business management of large, small, and medium-sized enterprises (SMEs) [3]. ERP enables the organization to gain a competitive advantage by storing resources and responding quickly to an ever-changing business environment [4]. However, using an ERP system is not just a computer project, but a kind of costly and risky investment that affects the initial processes and support of the company, organizational structure and its processes, existing systems in the organization and personal plans and tasks of employees [5, 6].

Therefore, to avoid spending a lot of time and money to implement ERP, which may eventually lead to the implementation of the implementation project and sometimes bankruptcy, it is necessary to provide tools and methods for managers and experts to prepare the banking network for this issue. This study aims to investigate the challenges of

* Corresponding author: somayeh_alavi61@yahoo.com

doi http://dx.doi.org/10. 28991/HEF-2021-02-01-02

$>$ This is an open access article under the CC-BY license (https://creativecommons.org/licenses/by/4.0/).

(C) Authors retain all copyrights. 
operating ERP in the banking network, which is an innovation of the present study. Through this research, it is possible to identify the indicators affecting ERP operations in the banking network and get acquainted with the solutions and challenges facing banks in implementing this system [7]. In Section 2, the related articles are reviewed. In the following, the reasons for the ERP failures are investigated. In the next section, the research methodology is mentioned and then the conclusions are presented.

\section{Literature Review}

\subsection{ERP}

The role of ERP in business activities is expanding rapidly, and in line with it, companies are forced to use sophisticated software to keep up with the complexity of products, services, and customer expectations as well as market pressures [8]. The term "ERP" essentially refers to the state in which a large organization is programmed to use its extensive enterprise resources. These systems were used in the past by most types of large industrial companies. However, its use has changed and is extremely comprehensive and pervasive [9]. This term can nowadays be referred to any type of company, no matter what industry is involved in them. In fact, ERP systems are used in all types of small and large organizations. The user organization needs to be equipped with two or more systems in order to use an ERP information system in organizations. Modern ERP systems can cover a wide range of functions and integrate them into a single database [8]. For instance, the functions such as human resources, supply chain management and control, customer relationship management and control, as well as financial affairs, production functions, and warehousing control functions are all based on software applications and have databases and internet networks. Today, all of these functions can continue under one system, which is the ERP system.

\subsection{Risk Assessment}

The word risk has been interpreted differently depending on its use in different contexts, and authors have come up with many definitions in this regard. Hence, it is different depending on the point of view, the tendencies and experiences of different people $[10,11]$. Theoretically, risk indicates the probability of deviating from the desired goal at a given time. The terms such as uncertainty or indefinite conditions, uncertainty about the future, etc. are defined in the risk theory [12]. It should be noted that risks do not always indicate the undesirable outcomes and may also represent opportunities. However, the fact that most risks have undesirable outcomes stimulates this thought in different people. Project Management Body of Knowledge (PBBOK) defines "risk" as follows: Risk is an uncertain situation or event that if it occurs, it will affect at least one of the objectives of the project. Goals can be the range, time, cost and quality.

The failure factor analysis approach and its effects is a systematic approach to identifying and preventing the occurrence of a problem in the product and its process that focuses on the prevention of defects, enhancing safety and enhancing the customer satisfaction [13]. Analysis of failure factors and their effects can be described as a set of targeted activities to identify and evaluate potential failures of products and processes and their effects [14].

\subsection{ERP and Risk Assessment}

ERP projects are the IT projects with a high failure rate. According to reports published in August 2017 by the site of ERPFOCUS, over $60 \%$ of the ERP projects fail, and $57 \%$ of them are implemented later than the expected time. Based on another study that was done by SGI about the information technology projects, it was found that $34 \%$ of these projects were delayed or confronted by budget deficiency, $31 \%$ were abandoned or faced changes, and only $24 \%$ were finished on time and with the considered budget [3].

The above points indicate that thorough and rigorous studies should be carried out about the ERP projects and the best alternative should be selected, and all the managers, experts, technicians, etc. should be ready to use a new system with standardized processes considering the improvement and modification of the information flow in their most important activities. If the above issues are properly done during the processes ERP implementation, the required developments will be certain, and it is in such a case that the organization can benefit from the advantages of proper information systems in the not too distant future. One of the reasons for the failure of ERP projects is that the relevant managers do not use acceptable criteria to evaluate and manage the risks involved in these projects [15]. Risk management of enterprise resource planning projects is largely recognized as a complicated task by academics and professionals. Interactions often occur between risk factors that would likely have indirect effects on the overall project performance. Unfortunately, the implications of interdependence are usually underestimated by project managers and decision makers because risk assessment is so difficult for them. ERP projects are very sophisticated approaches in business companies and hence, their risk factors include various technological, managerial, psychological and sociological aspects. Risk factors have direct and indirect impact on the projects and play a great role in the success or failure of the projects. Thus, consideration and evaluation of these factors are crucial for achieving the desired results and the purpose of implementing these costly projects. Therefore, considering the organizational consequences and existing risks involved in the ERP projects, it is quite important for companies to find the required ways to maximize the chances of success in focusing the selecting the ERP system [16]. 
Undoubtedly identifying the risk factors that an organization will face during the execution of these projects and their effects on the success or failure of the project can have a significant impact on enhancing readiness to deal with risk factors and minimize the likelihood of project failure. Therefore, identifying the risks on the one hand and classifying them in a way that is perceivable for the managers is very important [3]. Based on the investigations, there are few studied regarding ERP risk assessment. Moreover, the risks associated with establishment an ERP project under the BSC dimensions are not yet classified in the literature. Research background were presented in Table 1.

\subsection{The Causes of ERP Failure}

Despite the many benefits of implementing ERP, organizations seldom implement it fully [17, 18]. Figure 1 lists some ERP project failure factors in the Balanced Scorecard (BSC) category. The BSC is a combination of organizational performance metrics that include current, past and future performance metrics. In a balanced scorecard, non-financial criteria are placed next to financial criteria. The primary purpose of the BSC model is to apply the goals and vision of the organization in practice. These goals and indicators look at the organization's performance in four aspects: financial, customer, growth and learning, and internal processes.

Table 1. Summary of literature review

\begin{tabular}{lll}
\hline \multicolumn{1}{c}{ Reference } & \multicolumn{1}{c}{ Research Aim } & Research methodology \\
\hline Baykasoğlu and Gölcük (2020) [19] & Valuating ERP implementation risks & Fuzzy FMEA \\
Kumar (2018) [20] & Systematic process safety and mitigation, mapping in ERP & Theoretical framework \\
Dachyar and Prawira (2016) [21] & Improve ERP post-implementation & Fuzzy FMEA and Grey Relational Analysis \\
Jamshidi et al. (2015) [22] & Risk assessment in ERP projects & FMEA \\
Zaitar (2014) [23] & Risk assessment in ERP projects life cycle & Fuzzy FMEA and Grey Relational Analysis \\
Jamshidi et al. (2014) [24] & Risk assessment in ERP maintenance & FMEA and Data Mart \\
Sahno et al. (2013) [25] & Performance level assessment of knowledge management framework \\
Karaulova et al. (2011) [26] & Design of reliable production route system & FMEA \\
Shirouyehzad et al. (2009) [27] & Control of failure preferences in ERP & FMEA \\
Hsiao et al. (2007) [28] & Key failure factors of ERP & QFD and FMEA \\
\hline
\end{tabular}

\section{Stockholders' Risks}

Disrupting activities and reducing the response to the customers at the start of the project; Lack of CRM and ERP integration; Incorrect selection and insufficient number of ERP modules; Lack of management in appropriation with changes; Inadequate and inefficient infrastructure of information technology; Low participation of key users of the project; Improper management, selection and control of consultants, ERP vendors and subcontractors; Lack of commitment and support of the senior managers [29-31].

\section{Growth and Learning Risks}

Creating dependency on system providers; Lack of user support and resistance to change; Lack of commitment, motivation and professionalism of ERP support and maintenance team members; Insufficient expert analysers with commercial and technical knowledge; Lack of familiarity with the type of processes and their implementation in the organization and lack of sufficient knowledge of the failures of the existing processes; Improper culturalization about the users; Misunderstanding the needs of the organization; Lack of using effective individuals in executing the project; Inappropriate training on new processes, performance and using the ERP system [29, 32, 33]

BSC

Process Risks Confronting new requirements at the time of implementation;
Wrong selection of implementation methodology; Lack of Wrong selection of implementation methodology; Lack of module; Inappropriate prioritization of existing needs for implementation; Lack of identifying the weaknesses of the ERP project; Inconformity and incorrect estimation of the amount of organization processes covered by ERP; Lack of proper testing prior to implementation of ERP system; Long delay in the trend of project implementation; Uncertain and ambiguous changes in structure, goals, mission of the organization and continuous changes in requirements; during deployment; Poor planning and management of the project; Complexity of ERP modules; Lack of investigating the existing system conditions; Inattention to the re-engineering of the processes; Lack of perspective and specific strategies in ERP implementation and inefficient strategic thinking and planning [3438].
Concentration of project managers on financial and technical aspects of ERP implementation project and neglecting nontechnical issues such as individuals; Inadequate and non-realistic budget; High ERP support and maintenance costs [33, 39].

Figure 1. ERP project failure factors based on BSC categorization 


\section{Research Methodology}

Since this study aims to identify and prioritize ERP implementation risks in the banking industry, the statistical population of the present study is all branches of one of the banks in Iran. A questionnaire was sent to the IT managers of all departments. The questionnaire used in this study was designed based on the research model and FMEA to measure the occurrence, severity, and detection. Solutions are also prioritized using the TOPSIS technique. Figure 2 shows the research methodology.

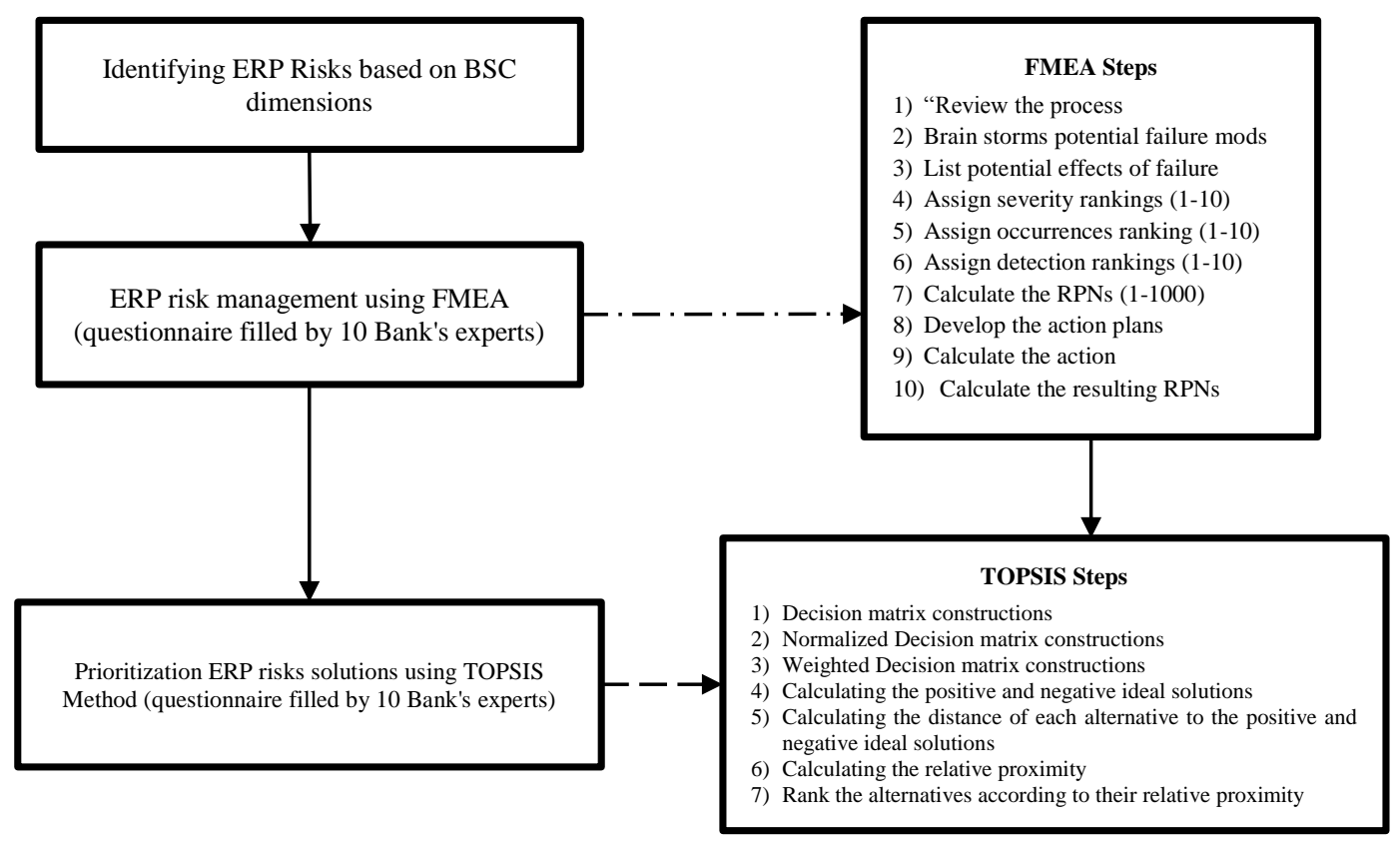

Figure 2. The research methodology

\section{Research Results and Findings}

After extracting the risks faced by the banking industry using the Delphi outputs, the questionnaire was redistributed among the bank experts. They were asked to measure the probability of risk occurrence, the severity of and detection a value ranging from 1 to 10 to obtain the RPNs. Finally, by averaging the obtained RPNs, the risks were ranked using FMEA in the form of BSC, which were obtained according to Table 2. Finally, the average RPNs obtained in each dimension are calculated and then the BSC dimensions ranked according to the below table.

Table 2. ERP-related risks in the banking network

\begin{tabular}{|c|c|c|c|c|}
\hline Final Dimension rank & RPN & Risk & Row & BSC dimension \\
\hline \multirow{4}{*}{$\begin{array}{l}\text { Mean RPN=315.41 } \\
\text { Rank=1 }\end{array}$} & 405.22 & Disrupting activities and reducing customer response at the beginning of the project & 1 & \multirow{4}{*}{ Shareholders } \\
\hline & 297.78 & Inefficient and insufficient IT infrastructure & 2 & \\
\hline & 287.44 & Incorrect selection and insufficient number of ERP modules & 3 & \\
\hline & 271.22 & No proper management of changes & 4 & \\
\hline \multirow{6}{*}{$\begin{array}{l}\text { Mean RPN=279.66 } \\
\text { Rank=3 }\end{array}$} & 362.77 & No familiarity with the type of projects and how to implement them & 1 & \multirow{6}{*}{$\begin{array}{c}\text { Growth and learning } \\
\text { dimension }\end{array}$} \\
\hline & 307.00 & Dependence on system suppliers & 2 & \\
\hline & 304.89 & No commitment, motivation and professionalism of ERP support team members & 3 & \\
\hline & 278.22 & Misunderstanding the enterprise needs & 4 & \\
\hline & 253.89 & No user support and resistance to change & 5 & \\
\hline & 171.22 & Improper culture building for users & 6 & \\
\hline \multirow{5}{*}{$\begin{array}{l}\text { Mean RPN=302.93 } \\
\text { Rank=2 }\end{array}$} & 425.78 & Meeting new needs during implementation & 1 & \multirow{5}{*}{ Process dimension } \\
\hline & 366.11 & Long delay in the project implementation process & 2 & \\
\hline & 281.77 & No proper testing before implementing ERP system & 3 & \\
\hline & 254.66 & No coordination between users in different units related to a module & 4 & \\
\hline & 186.33 & Failure to identify weaknesses in the ERP project & 5 & \\
\hline \multirow{2}{*}{$\begin{array}{l}\text { Mean RPN=240.99 } \\
\text { Rank=4 }\end{array}$} & 285.11 & High costs of ERP support and maintenance team & & \multirow{2}{*}{ Financial dimension } \\
\hline & 196.88 & Insufficient and unrealistic budget & & \\
\hline
\end{tabular}


After prioritizing the risks based on the dimensions of the BSC, suggestions will be made to address each risk. After presenting the solutions, it is necessary to prioritize the solutions. Based on this, the TOPSIS method has been selected to prioritize solutions. Experts were first asked to introduce three criteria for prioritizing the solution. The decision matrix is formed after introducing the three criteria of cost, time, and feasibility for multiple solutions. Finally, the solutions are prioritized using the BT TOPSIS SOLVER software program as shown in Table 3.

Table 3. ERP-related risk management strategies

\begin{tabular}{|c|c|c|c|c|c|}
\hline Risk & Solutions & Cost & Time & Feasibility & $\begin{array}{c}\text { TOPSIS } \\
\text { Rank }\end{array}$ \\
\hline \multirow{3}{*}{$\begin{array}{l}\text { Disrupting activities } \\
\text { and reducing customer } \\
\text { response }\end{array}$} & Implementation of ERP first in a test environment and on a trial basis & 1 & 3 & 9 & 1 \\
\hline & Informing the customers & 5 & 3 & 9 & 2 \\
\hline & $\begin{array}{l}\text { Minimization of customer presence by encouraging them to use modern } \\
\text { banking }\end{array}$ & 3 & 7 & 9 & 3 \\
\hline \multirow{3}{*}{$\begin{array}{l}\text { No user support and } \\
\text { resistance to change }\end{array}$} & The staff participation in the project & 3 & 5 & 7 & 1 \\
\hline & Informing employees of the benefits of implementing ERP in the organization & 3 & 7 & 9 & 2 \\
\hline & $\begin{array}{l}\text { Holding training courses and using motivational techniques to improve the level } \\
\text { of acceptance of change in the whole organization }\end{array}$ & 5 & 5 & 7 & 3 \\
\hline \multirow{2}{*}{$\begin{array}{l}\text { Lack of familiarity } \\
\text { with the type of } \\
\text { projects and how to } \\
\text { implement them in the } \\
\text { organization }\end{array}$} & $\begin{array}{l}\text { Review of organizational activities, identification of weaknesses and } \\
\text { shortcomings of each process and implementation of the necessary measures to } \\
\text { eliminate the identified shortcomings. }\end{array}$ & 5 & 9 & 5 & 1 \\
\hline & $\begin{array}{l}\text { Identification of organizational processes and implementation of BPM business } \\
\text { process management in the organization in order to accurately execute } \\
\text { processes: The integration of BPM and ERP from the perspective of researchers } \\
\text { has a significant impact on the implementation of ERP and achieving agility. }\end{array}$ & 9 & 5 & 7 & 2 \\
\hline \multirow{2}{*}{$\begin{array}{l}\text { Improper culture } \\
\text { building for users }\end{array}$} & Culture building that must be done before the integration & 7 & 7 & 9 & 1 \\
\hline & Holding training classes & 7 & 3 & 7 & 2 \\
\hline \multirow{3}{*}{$\begin{array}{l}\text { Misunderstanding the } \\
\text { enterprise needs }\end{array}$} & Use of an in-house analyst in ERP implementation & 1 & 5 & 9 & 1 \\
\hline & The staff participation in the project & 1 & 3 & 7 & 2 \\
\hline & $\begin{array}{l}\text { Presence of executive actors in the implementation of the organization's } \\
\text { business process management }\end{array}$ & 9 & 3 & 9 & 3 \\
\hline \multirow{6}{*}{$\begin{array}{l}\text { No coordination } \\
\text { between users in } \\
\text { different units related } \\
\text { to a module }\end{array}$} & Delegation of decision-making power & 1 & 3 & 9 & 1 \\
\hline & Proper composition of the project team & 1 & 3 & 9 & 2 \\
\hline & Proper assignment of responsibilities & 1 & 5 & 9 & 3 \\
\hline & There is a constant connection between the implementation team and the staff & 1 & 5 & 9 & 4 \\
\hline & Encouragement for communication and collaboration between different units & 1 & 5 & 9 & 5 \\
\hline & Use of collaborative management and project manager projects & 1 & 9 & 9 & 6 \\
\hline \multirow{4}{*}{$\begin{array}{l}\text { No proper testing } \\
\text { before implementing } \\
\text { ERP }\end{array}$} & Selecting the appropriate implementation approach & 5 & 7 & 5 & 1 \\
\hline & Offline testing and commissioning system to find system bugs & 7 & 7 & 9 & 2 \\
\hline & Proper planning & 7 & 5 & 9 & 3 \\
\hline & Accurate forecasting of needs & 3 & 1 & 9 & 4 \\
\hline \multirow{4}{*}{ Meeting new needs } & Consultation with executive staff & 1 & 3 & 9 & 1 \\
\hline & Proper management of expectations & 1 & 7 & 7 & 2 \\
\hline & Continuous communication with external stakeholders & 5 & 7 & 7 & 3 \\
\hline & Implementation of the right strategy & 7 & 9 & 7 & 4 \\
\hline \multirow{2}{*}{$\begin{array}{l}\text { Failure to identify } \\
\text { weaknesses in the ERP } \\
\text { project }\end{array}$} & Use of benchmarking to emulate ERP banks better & 3 & 5 & 9 & 1 \\
\hline & Use of experienced individuals & 7 & 7 & 7 & 2 \\
\hline \multirow{3}{*}{$\begin{array}{l}\text { A long delay in the } \\
\text { project implementation } \\
\text { process }\end{array}$} & Precise and clear definition of policy and goals & 3 & 7 & 7 & 1 \\
\hline & $\begin{array}{l}\text { Accurate forecasting of requirements and financial budget required for project } \\
\text { implementation }\end{array}$ & 5 & 5 & 9 & 2 \\
\hline & Using knowledgeable and capable people, re-engineering processes & 9 & 5 & 7 & 3 \\
\hline \multirow{5}{*}{$\begin{array}{l}\text { Ambiguous changes in } \\
\text { the structure, goals, } \\
\text { mission of the } \\
\text { organization and } \\
\text { successive changes }\end{array}$} & Strong project management & 1 & 7 & 9 & 1 \\
\hline & Realistic planning & 3 & 7 & 9 & 2 \\
\hline & Change management & 5 & 3 & 7 & 3 \\
\hline & Sustainable support for senior management & 1 & 7 & 7 & 4 \\
\hline & Crisis management and considering the worst cases & 5 & 5 & 7 & 5 \\
\hline
\end{tabular}




\section{Conclusion}

After categorizing the organization's risks in four dimensions of stakeholders, growth and learning, process, and finance and ranking them based on FMEA, it was determined that the stakeholder dimension is in the first place, which shows the effectiveness of this dimension in advancing ERP implementation. The second place is given to growth and learning, which can be concluded to what extent education and knowledge management can reveal their effects on the project. The third and fourth ranks are the dimensions of process and finance, respectively, which, although the concern of most organizations to implement ERP is the financial dimension, is in the last rank of the category. According to the prioritization given to bank managers, it is suggested to define practical corrective actions in the organization and take the necessary follow-ups to reduce the risk or reduce the severity of the occurrence and increase the diagnosis. Future researchers are encouraged to explore how to implement the barriers to ERP implementation known in the present study in the banking network.

\section{Declarations}

\subsection{Author Contributions}

S.A., S.P., and S.M. contributed to the design and implementation of the research, to the analysis of the results and to the writing of the manuscript. All authors have read and agreed to the published version of the manuscript.

\subsection{Data Availability Statement}

The data presented in this study are available in article.

\subsection{Funding}

The authors received no financial support for the research, authorship, and/or publication of this article.

\subsection{Institutional Review Board Statement}

Not applicable.

\subsection{Informed Consent Statement}

Not applicable.

\subsection{Declaration of Competing Interest}

The authors declare that there is no conflict of interests regarding the publication of this manuscript. In addition, the ethical issues, including plagiarism, informed consent, misconduct, data fabrication and/or falsification, double publication and/or submission, and redundancies have been completely observed by the authors.

\section{References}

[1] Alavi, S., Nematbakhsh, N., \& Zeraati, V. (2018). A sustainable model for deployment of mobile learning in schools. International Journal of Mobile Learning and Organisation, 12(2), 113-142. doi:10.1504/IJMLO.2018.090843.

[2] Nyame, G. (2017). A Customer-Complaint Analyzer for E-Banking Services: The Context of the Ghanaian Banking Industry. Information and Knowledge Management, 7(1), 1-9.

[3] Zeraati, V., Alavi, S., Ramezanian, M., \& Bagheri, A. (2020). Providing a Model for Achieving Organizational Agility with Emphasis on Business Process Management (BPM). International Journal of Process Management and Benchmarking, 1(1), 1. doi:10.1504/ijpmb.2020.10033708

[4] Elgohary, E. (2019). The Role of ERP Capabilities in Achieving Competitive Advantage: An Empirical Study on Dakahlia Governorate Companies, Egypt. Electronic Journal of Information Systems in Developing Countries, 85(4), 12085. doi:10.1002/isd2.12085.

[5] Barth, C., \& Koch, S. (2019). Critical success factors in ERP upgrade projects. Industrial Management and Data Systems, 119(3), 656-675. doi:10.1108/IMDS-01-2018-0016.

[6] Kirmizi, M., \& Kocaoglu, B. (2021). The influencing factors of enterprise resource planning (ERP) readiness stage on enterprise resource planning project success: a project manager's perspective. Kybernetes. doi:10.1108/K-11-2020-0812.

[7] Triki, C., Mirmohammadsadeghi, S., \& Piya, S. (2017). Heuristic methods for the periodic Shipper Lane Selection Problem in transportation auctions. Computers and Industrial Engineering, 106, 182-191. doi:10.1016/j.cie.2017.02.005.

[8] Alavi, S., \& Eklili, H. (2021). Identifying and Prioritize ERP Risks Implementation Using FMEA and Heuristic AHP in SNOWA Corporation. Industrial Management Journal, 16, 161-177. 
[9] Ghani, U., Signal, N., Niazi, I. K., \& Taylor, D. (2020). ERP based measures of cognitive workload: A review. Neuroscience and Biobehavioral Reviews, 118, 18-26. doi:10.1016/j.neubiorev.2020.07.020.

[10] Liu, H.-C. (2019). Improved FMEA Methods for Proactive Healthcare Risk Analysis. In Improved FMEA Methods for Proactive Healthcare Risk Analysis. Springer. doi:10.1007/978-981-13-6366-5.

[11] Alavi, S., \& Mirmohammadsadeghi, S. (2021). Introducing a Green Agile Workforce. Journal of Soft Computing and Decision Support Systems, 8, 18-24.

[12] Skorupka, D. (2008). Identification and Initial Risk Assessment of Construction Projects in Poland. Journal of Management in Engineering, 24(3), 120-127. doi:10.1061/(asce)0742-597x(2008)24:3(120).

[13] Rastayesh, S., Bahrebar, S., Blaabjerg, F., Zhou, D., Wang, H., \& Sørensen, J. D. (2020). A system engineering approach using FMEA and bayesian network for risk analysis-a case study. Sustainability (Switzerland), 12(1), 1-18. doi:10.3390/SU12010077.

[14] Chen, T. H. (2020). Do you know your customer? Bank risk assessment based on machine learning. Applied Soft Computing Journal, 86, 105779. doi:10.1016/j.asoc.2019.105779.

[15] Taghipour, M., Shabrang, M., Habibi, M. H., \& Shamami, N. (2020). Assessment and Analysis of Risk Associated with the Implementation of Enterprise Resource Planning (ERP) Project Using FMEA Technique (Including Case-Study). Management, 3(1), 29-46.

[16] Mirmohammadsadeghi, S., \& Ahmed, S. (2015). Memetic Heuristic Approach for Solving Truck and Trailer Routing Problems with Stochastic Demands and Time Windows. Networks and Spatial Economics, 15(4), 1093-1115. doi:10.1007/s11067-0149282-2.

[17] Wang, W., \& Wu, Y. (2019). A Tale of Two Systems. Handbook of Research on the Evolution of IT and the Rise of E-Society, 162-178. doi:10.4018/978-1-5225-7214-5.ch008.

[18] Yan, X., Yu, G., \& Ji, P. (2019). ERP investment and implementation between China and US: difference and enlightenment. Information Technology and Management, 20(4), 175-185. doi:10.1007/s10799-019-00301-4.

[19] Baykasoğlu, A., \& Gölcük, İ. (2020). Comprehensive fuzzy FMEA model: a case study of ERP implementation risks. Operational Research, 20(2), 795-826. doi:10.1007/s12351-017-0338-1.

[20] Kumar, A. (2018). Systematic process safety and mitigation by asset integrity managment - Case study. Offshore Technology Conference Asia 2018, OTCA 2018. doi:10.4043/28223-ms.

[21] Dachyar, M., \& Prawira, Y. (2016). A study to improve enterprise resources planning post-implementation in Indonesian industries. Knowledge, Service, Tourism and Hospitality-Proceedings of the Annual International Conference on Management and Technology in Knowledge, Service, Tourism and Hospitality, SERVE 2015, 227-232. doi:10.1201/b21184-40.

[22] Jamshidi, A., Rahimi, S. A., Ait-Kadi, D., Rebaiaia, M. L., \& Ruiz, A. (2015). Risk assessment in ERP projects using an integrated method. 3rd International Conference on Control, Engineering and Information Technology, CEIT 2015 , 1-5. doi:10.1109/CEIT.2015.7233184.

[23] Zaitar, Y. (2014). Risk assessment in ERP projects life cycle: The application of FMEA approach. International Review on Computers and Software, 9(11), 1888-1895. doi:10.15866/irecos.v9i11.4466.

[24] Jamshidi, A., Rahimi, S. A., Bartolome, A. R., \& Ait-Kadi, D. (2014). A new framework for risk assessment in ERP maintenance. Proceedings - Annual Reliability and Maintainability Symposium, 1-6. doi:10.1109/RAMS.2014.6798515.

[25] Sahno, J., Sevtsenko, E., \& Karaulova, T. (2013). Knowledge management framework for Six Sigma performance level assessment. In Advances in Intelligent Systems and Computing: Vol. 206 AISC (pp. 255-267). Springer. doi:10.1007/978-3642-36981-0_25.

[26] Karaulova, T., Pribytkova, M., Sahno, J., \& Shevtshenko, E. (2011). Design of reliable production route system. Annals of DAAAM and Proceedings of the International DAAAM Symposium, 539-540. doi:10.2507/22nd.daaam.proceedings.266.

[27] Shirouyehzad, H., Badakhshian, M., \& Dabestani, R. (2009). The identification and control of failure preferences in ERP implementation using FMEA. In WMSCI 2009-The 13th World Multi-Conference on Systemics, Cybernetics and Informatics, Jointly with the 15th International Conference on Information Systems Analysis and Synthesis, ISAS 2009 - Proc.

[28] Hsiao, Y. Du, Yang, C. C., Lin, W. T., \& Lee, W. C. (2007). A study on key failure factors for introducing enterprise resource planning. Human Systems Management, 26(2), 139-152. doi:10.3233/hsm-2007-26206.

[29] Tarn, J. M., Yen, D. C., \& Beaumont, M. (2002). Exploring the rationales for ERP and SCM integration. Industrial Management and Data Systems, 102(1), 26-34. doi:10.1108/02635570210414631.

[30] Amid, A., Moalagh, M., \& Zare Ravasan, A. (2012). Identification and classification of ERP critical failure factors in Iranian industries. Information Systems, 37(3), 227-237. doi:10.1016/j.is.2011.10.010. 
[31] Ganesh, L., \& Mehta, A. (2010). Critical Success Factors for Successful Enterprise Resource Planning Implementation at Indian SMEs. International Journal of Business, 1(1), 65-78.

[32] Aloini, D., Dulmin, R., \& Mininno, V. (2012). Risk assessment in ERP projects. Information Systems, 37(3), $183-199$. doi:10.1016/j.is.2011.10.001.

[33] Bharathi, S. V., Raman, R., \& Pramod, D. (2014). A FPN based risk assessment model for ERP implementation in small and medium enterprises. Middle - East Journal of Scientific Research, 19(6), 747-759. doi:10.5829/idosi.mejsr.2014.19.6.12515.

[34] Kim, Y., Lee, Z., \& Gosain, S. (2005). Impediments to successful ERP implementation process. Business Process Management Journal, 11(2), 158-170. doi:10.1108/14637150510591156.

[35] Bansal, V., \& Negi, T. (2008). A metric for ERP complexity. Lecture Notes in Business Information Processing, 7 LNBIP, 369379. doi:10.1007/978-3-540-79396-0_32.

[36] ERKAN, T. E. (2009). BPR Effect on ERP Implementation: a Comparative Case Study. International Journal of Economics and Management Engineering, 3(6), 1143-1146. doi:10.5281/zenodo.1085433.

[37] Estefania, T. V., Samir, L., Robert, P., Patrice, D., \& Alexandre, M. (2018). The integration of ERP and inter-intra organizational information systems: A Literature Review. IFAC-PapersOnLine, 51(11), 1212-1217. doi:10.1016/j.ifacol.2018.08.425.

[38] Kilimis, P., Zou, W., Lehmann, M., \& Berger, U. (2019). A survey on digitalization for SMEs in Brandenburg, Germany. IFACPapersOnLine, 52(13), 2140-2145. doi:10.1016/j.ifacol.2019.11.522.

[39] Hermansson, C. (2018). Can self-assessed financial risk measures explain and predict bank customers' objective financial risk? Journal of Economic Behavior and Organization, 148, 226-240. doi:10.1016/j.jebo.2018.02.018. 